\title{
A transformed fish cell line expressing a green fluorescent protein-luciferase fusion gene responding to cellular stress
}

\author{
A. Molina ${ }^{1}$, R. Carpeaux, J.A. Martial, M. Muller* \\ Laboratoire de Biologie Moléculaire et Génie Génétique, Université de Liège, Institut de Chimie B6, B-4000 Sart-Tilman, Belgium
}

Accepted 18 September 2001

\begin{abstract}
We obtained a stable transformed fish (EPC) cell line containing a reporter gene under the control of the tilapia HSP70 promoter. Expression of the reporter gene, coding for a green fluorescent protein (GFP)-luciferase fusion protein, was assessed by measuring the luciferase enzymatic activity by luminometry and the GFP expression by fluorescence microscopy and flow cytometry. The clone was characterized for its capacity to respond to heat shock treatment. The results show high induction after $1 \mathrm{~h}$ at $37{ }^{\circ} \mathrm{C}$ of treatment, up to 500-fold. In addition, its convenience to detect a large range of cellular stressors was evaluated. We observed high induction when $\mathrm{Cd}^{2+}, \mathrm{Zn}^{2+}, \mathrm{Hg}^{2+}$ or $\mathrm{Cu}^{2+}$ was added, but not $\mathrm{Pb}^{2+}$. In addition, activation of the reporter gene was observed in the presence of other compounds such as acetyl chloride, tetrachlorophenol, chloroacetamide and sodium arsenite. In conclusion, this cell line can be used as a rapid, cheap and easy biological test to determine cellular stress induced by environmental pollutants, alone or in conjunction with other, more specific assays. (C) 2002 Elsevier Science Ltd. All rights reserved.
\end{abstract}

Keywords: HSP70; Tilapia; Heat shock; Bioassay; GFP

\section{Introduction}

Aquatic organisms are exposed to a wide range of environmental compounds that very often are able to cause physiological or cellular stress. Individual cells then undergo many changes, among which the synthesis of proteins involved in the protection of the cell are probably the most studied. In addition to more specifically induced proteins such as cytochromes P450 (e.g. by dioxins) or metallothioneins (metal ions), a more general protection system is represented by the heat shock proteins (HSP). First identified as a set of proteins induced after heat shock in Drosophila (Ritossa, 1962), HSPs have since been found universally from bacteria to human.

The most important and most studied HSPs form the HSP70 family. HSP70s have been included in the large family of chaperones; they play essential roles in protein metabolism under normal and stress conditions, includ-

Abbreviations: GFP, green fluorescent protein; HSE, heat shock regulatory regions; HSF, heat shock factors; HSP, heat shock proteins; PBS, phosphate buffered saline.

* Corresponding author. Tel.: +32-4-366-4437; fax: + 32-4-3662968.

E-mail address:m.muller@ulg.ac.be (M. Muller).

1 Present address: Laboratorio de Biologia Molecular y Celular, Universidad Andres Bello, Av. Republica 237, Santiago de Chile, Chile. ing protein translocation, de novo protein folding and protection of unfolded proteins. While their binding to an unfolded polypeptide chain results in stabilization of the unfolded state, their controlled release may allow progression along the folding pathway (Hartl, 1996). Thus, HSP70s are thought to protect the cell from proteotoxic stress by preventing the irreversible loss of vital proteins and by facilitating their subsequent regeneration. The expression of HSP70 proteins is regulated by a variety of toxic compounds (Morimoto, 1998), according to its function most often at sublethal levels, and their induction following exposure to environmental stressors has been increasingly studied in recent years. The methods used in these studies range from direct detection of the protein in extracts from cells or whole organisms by SDS-PAGE-gel electrophoresis (Misra et al., 1989), specific detection of HSP70 by Western blotting (Dunlap and Matsumura, 1997; De Wachter et al., 1998) or detection of the induced HSP70 mRNA levels by RT-PCR (Steiner et al., 1998). Reporter gene assays using mammalian cells containing an expression construct based on a HSP70 promoter have also been described (Todd et al., 1995; Vincent et al., 1997; AïtAissa et al., 2000).

The expression of HSP70 is regulated by environmental and physiological stress, this regulation occurs mainly at the transcriptional level. The promoter region 
of hsp70 genes contains specific heat shock regulatory regions (HSEs) that bind the trans-acting heat shock factors (HSF). HSFs are required for the heat shock response, they are normally present in the cytoplasm in a monomeric form and, upon heat stress, form trimers and migrate to the nucleus to bind HSEs with high affinity (Morimoto, 1993, 1998; Rabindran et al., 1993; Sistonen et al., 1994). Recently, we reported the isolation and characterization of the tilapia (Oreochromis mossambicus) HSP70 gene including about $1 \mathrm{~kb}$ of regulatory sequences (Molina et al., 2000). We showed that the tilapia HSP70 promoter is able to confer ubiquitous and heat shock controlled transient expression to a reporter gene both in fish cells and in microinjected zebrafish embryos. In this study, we generated a fish cell line containing a reporter gene coding for a fusion protein between the luciferase and the green fluorescent protein (GFP). Expression of this protein can be detected both by measuring the luciferase activity in cell extracts and in living cells by the spontaneous fluorescence of the GFP. We characterize the heat shock response of this cell line and we evaluate the induction by a collection of environmental stressors.

\section{Materials and methods}

\subsection{Plasmid constructs}

The p0GL reporter plasmid, containing a cDNA coding for a fusion protein of GFP and the luciferase was previously described (Day et al., 1998). The wildtype promoter was excised from the tiHSP70-1.0LacZ (Molina et al., 2000) by NotI and inserted into the p0GL to obtain the tiHSP70-1.0GL construct.

\subsection{Cell culture}

EPC cells (Epithelioma Papulosum Cyprini), derived from carp epidermal herpes virus-induced hyperplasia lesions (Fijan et al., 1983), were grown in Glasgow MEM (BHK-21) medium supplemented with $10 \%$ fetal bovine serum and $1 \%$ penicillin-streptomycin at $24{ }^{\circ} \mathrm{C}$ in $5 \% \mathrm{CO}_{2}$.

\subsection{Stable transformed cell line}

Vectors tiHSP70-1.0GL and pcDNA6/V5-HisB (Invitrogen $^{\mathrm{TM}}$, Carlsbad, US) were co-transfected into EPC cells by using the lipofectAMINE PLUS reagent (GIBCO-BRL, Gaithersburg, MD, US) according to the manufacturer's instructions. $24 \mathrm{~h}$ after transfection, the cells were cloned by limiting dilution into a $75 \mathrm{~cm}^{2}$ plate in the presence of $5 \mu \mathrm{pg} / \mathrm{ml}$ Blasticidin (Invitrogen). After 2 weeks, the cells were heat shocked and green fluorescent colonies were selected and transferred into a 24-well plate. After growing, clones were tested for their efficiency to respond to heat shock.

Heat and chemical shocks were performed by seeding the cells $\left(8 \times 10^{5}\right.$ cells/well in six-well and $10^{4}$ cells/well in 96-well plates) in fresh medium. After $72 \mathrm{~h}$, the various chemicals were added to the medium for $12 \mathrm{~h}$ or a heat shock was performed by exposing the plate previously sealed with parafilm in a thermoregulated bath at $37^{\circ} \mathrm{C}$. After the treatment, the cells were returned for $4 \mathrm{~h}$ at $24{ }^{\circ} \mathrm{C}$ for recovery. The cells were washed twice in phosphate buffered saline (PBS) and resuspended in lysis buffer (Brasier et al., 1989). The luciferase activity was determined in a multilabel counter (Wallac Victor ${ }^{2}$ from Perkin-Elmer Life Sciences, Turku, Finland). The luciferase activity in these assays was normalized to the total cell number, as determined by protein concentration (Bradford assay, Biorad, Hercules, US) for experiments performed in six-well plates, or DNA concentration for 96-well plates using the Pico Green dsDNA ${ }^{\circledR}$ Quantification reagent kit (Molecular Probes, Eugene, OR, US) according to the supplier's instructions. Control experiments had been performed to confirm that estimation of the cell number by measuring total DNA amount correlated well with that based on total protein amounts. A consistent decrease in the DNA concentration of the total cell extracts after specific treatments was indicative of cell death and was used as an estimate of the toxicity of the treatment. Experiments were performed in triplicates and repeated at least twice.

\subsection{Flow cytometry}

The cells were harvested by trypsinization, washed and resuspended in PBS buffer for cytometric analysis. Cytometric analysis was performed using an EPICS ${ }^{\circledR}$ XL-MCL flow cytometer (Becton-Dickinson Immunocytometry Systems, San Jose, CA, USA) equipped with a water-cooled argon laser emitting at $488 \mathrm{~nm}$. Analysis was performed using System ${ }^{\mathrm{TM}}$ Version 1.0 software (Becton-Dickinson). Green fluorescence was measured using a $530 \pm 30 \mathrm{~nm}$ band pass filter. Data were collected from 10,000 events for each sample. Signal amplification was adjusted to normalize the dot plot for analysis.

\subsection{Fluorescence microscopy}

For fluorescence detection, $10^{5}$ cells were seeded on two-chamber glass slides (LAB-TEK, Naperville, IL, US) in culture medium. After $72 \mathrm{~h}$ at $24^{\circ} \mathrm{C}$, the slides were incubated for $1 \mathrm{~h}$ at $37^{\circ} \mathrm{C}$ and returned at $24{ }^{\circ} \mathrm{C}$ for recovery. Four hours later, the GFPLuc fusion protein was visualized by using an Olympus BX60 microscope equipped with a ColorView8 device camera and analySIS ${ }^{\circledR} 3.0$ imaging software (Soft Imaging System, Münster, Germany). 


\section{Results}

\subsection{Generation of a stable reporter cell line}

We showed previously that the plasmid construct tiHSP70-1.0GL, containing the tilapia HSP70 promoter driving a reporter gene coding for a fusion protein between the GFP and the luciferase, was able to mediate a strong heat shock response in transient expression experiments (Molina et al., 2001). To obtain a cell line carrying an easily detectable reporter gene for environmental pollutants, we generated a stable cell line transformed with the tiHSP70-1.0GL construct. Taking advantage of the teleost origin of its regulatory regions, we decided to use carp EPC cells with this aim.

After transfection, the cells were left for 1 week on selective medium and several isolated clones were tested for their ability to respond to heat shock treatment (data not shown). Based on the requirement for a clearly detectable basal level activity and a high heat shock response, one of them (EPCtiHSP70) was selected for further characterization.

The EPCtiHSP70 cellular clone was submitted to a heat shock at $37^{\circ} \mathrm{C}$ for $1 \mathrm{~h}$ and the induced luciferase expression was followed for $30 \mathrm{~h}$. A 160-fold induction was already observed after $2 \mathrm{~h}$ (Fig. 1A), which further increased up to 400 -fold after 4 and $6 \mathrm{~h}$. Longer incubation times resulted in a gradual decrease, probably reflecting the degradation of the luciferase enzyme in the cells. Consequently, expression was tested after $4 \mathrm{~h}$ in the following experiments. The effect of various temperatures on tiHSP70 promoter stimulation was also tested (Fig. 1B). A clear signal was observed in EPCtiHSP70 cells only after $1 \mathrm{~h}$ at $32{ }^{\circ} \mathrm{C}$ and the strongest response was obtained at $37{ }^{\circ} \mathrm{C}$. Higher temperatures resulted in a drastic decrease of the signal, due to extensive cell death. No stimulation was obtained after a cold shock at $4{ }^{\circ} \mathrm{C}$.

When various time periods $(15,30,60$ and $120 \mathrm{~min})$ of the $37^{\circ} \mathrm{C}$ heat shock were tested on these cells (Fig. 1C), a gradual increase of the stimulation was observed up to $1 \mathrm{~h}$ of treatment, while longer exposures did not increase the signal. We also tested the effect of submitting the cell to a preceding cellular stress on tiHSP70 promoter stimulation. The cells were preshocked at $37{ }^{\circ} \mathrm{C}$ for $30 \mathrm{~min}$, left for $48 \mathrm{~h}$ and then heat shocked again for $30 \mathrm{~min}$. The response of pretreated cells was significantly lower than without the pretreatment. This phenomenon is known as heat shock resistance.

Taken together, our data indicate that the EPCtiHSP70 cell line displays a very strong and easily detectable heat shock response that presents several of the previously described characteristics (Jaattela, 1999; Samali et al., 1999; Molina et al., 2000).
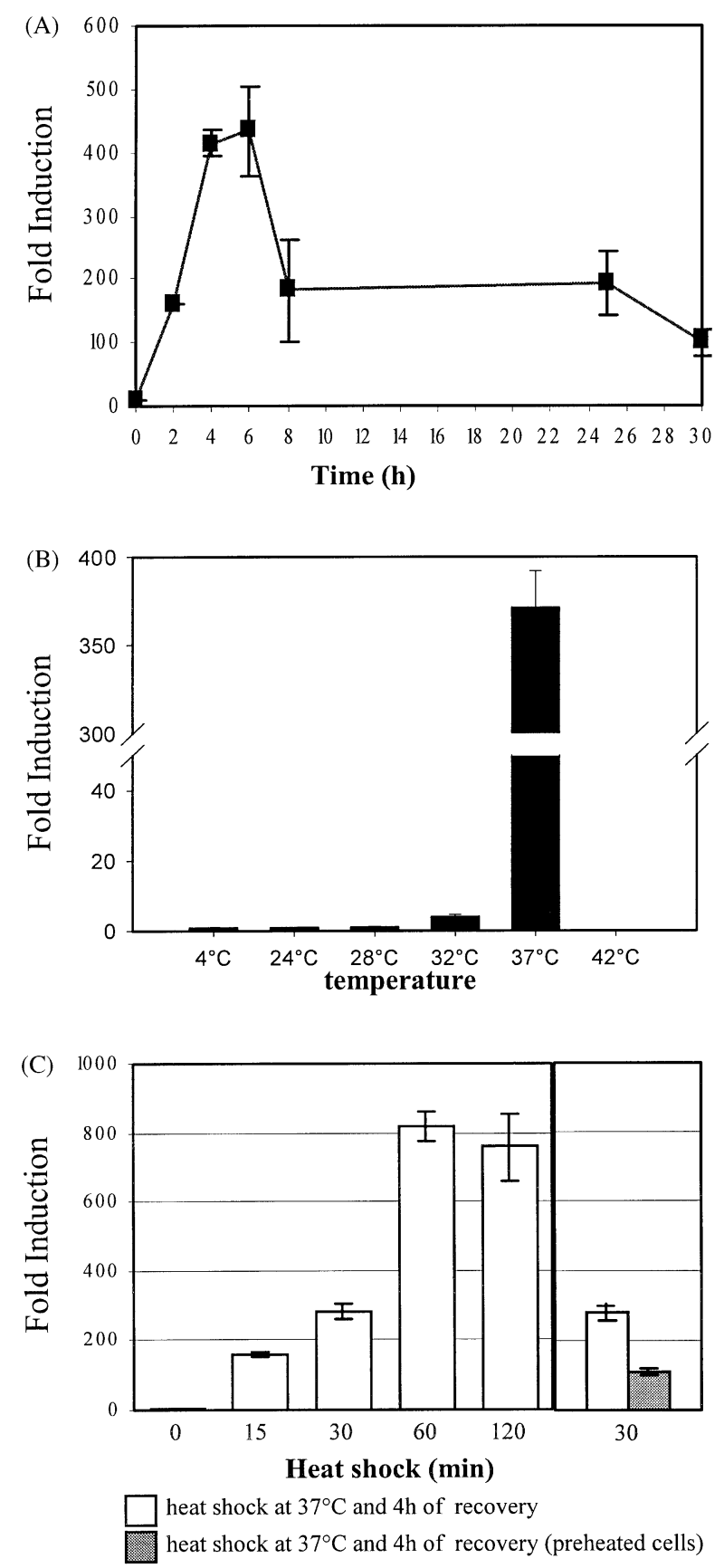

Fig. 1. Characterization of the EPCtiHSP70 cell line. (A) The cells were seeded in six-well plates and exposed to heat shock treatment for $1 \mathrm{~h}$ at $30^{\circ} \mathrm{C}$ and the luciferase activity in cell lysates was determined after various periods of time, as indicated. The experiments were performed in triplicates and repeated at least twice. The luciferase activity was normalized to the total protein amounts and the fold induction (mean \pm S.D.) relative to untreated control cells in one representative experiment is shown. (B) Luciferase expression was determined $4 \mathrm{~h}$ after heat shock treatment for $1 \mathrm{~h}$ at different temperatures. (C) Luciferase expression was measured $4 \mathrm{~h}$ after heat shock treatments performed for different time periods. The effect of a 30-min heat shock was also determined $48 \mathrm{~h}$ after a first 30 -min heat shock had been performed (right panel). 


\subsection{Detection of the GFP}

To further characterize the cell clone and to evaluate different methods to detect the heat shock response, control cells and treated cells were analyzed by fluorescence microscopy for the presence of active GFP protein (Plate 1). A strong green fluorescence was observed in about half of the cells only after heat shock, indicating that the GFPLuc fusion protein is functional in these cells.

GFP fluorescence of the cells was also monitored by flow cytometry (Fig. 2). Control cells homogeneously exhibited very low background fluorescence. After a 30 min heat shock, most of the cells (more than 90\%) displayed a strongly increased signal; two different cell populations, respectively with low and high fluorescence were observed. Treatment for $1 \mathrm{~h}$ resulted in a further shift of the cell population to a higher expression.

\section{Control}

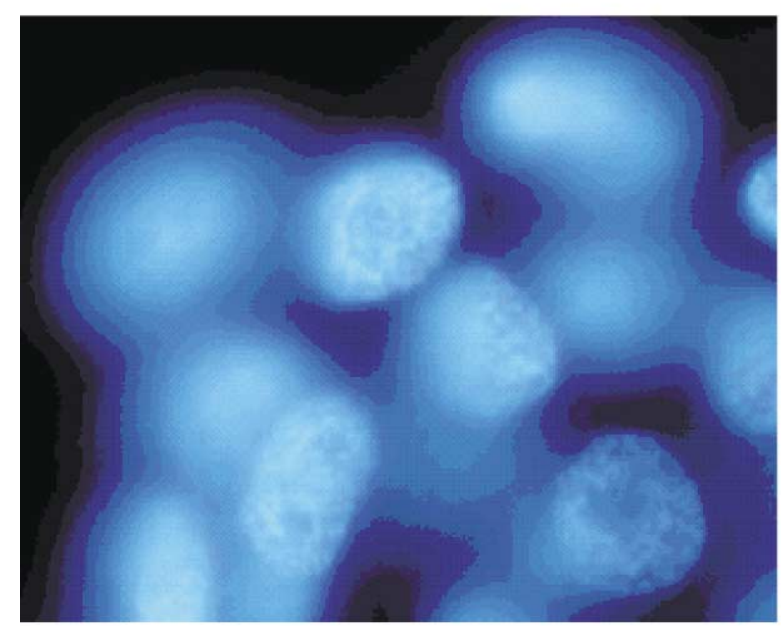

\subsection{Use of the reporter cell line to test environmental pollutants}

After characterizing the heat shock response of the EPCtiHSP70 clone, we decided to test different environmental pollutants for their ability to activate the expression of the GFPLuc reporter gene. To that purpose, we changed the setup of the experiments to a 96well plate system, taking advantage of the high transcriptional activity of the transgene in the EPCtiHSP70 clone. We first tested a well-known inducer of HSP genes, sodium arsenite, which leads to a clear 200-fold stimulation at $50 \mu \mathrm{M}$ (Fig. 3A) and is detectable at a concentration as low as $500 \mathrm{~nm}$ (five-fold induction). Higher concentrations (more than $250 \mu \mathrm{M}$ ) caused loss of the signal due to cell death, as detectable from the total DNA measurements (see also Discussion). Acetyl chloride was detected at $500 \mu \mathrm{M}$, gave a clear signal at

Heat shock 1 h at $37^{\circ} \mathrm{C}$

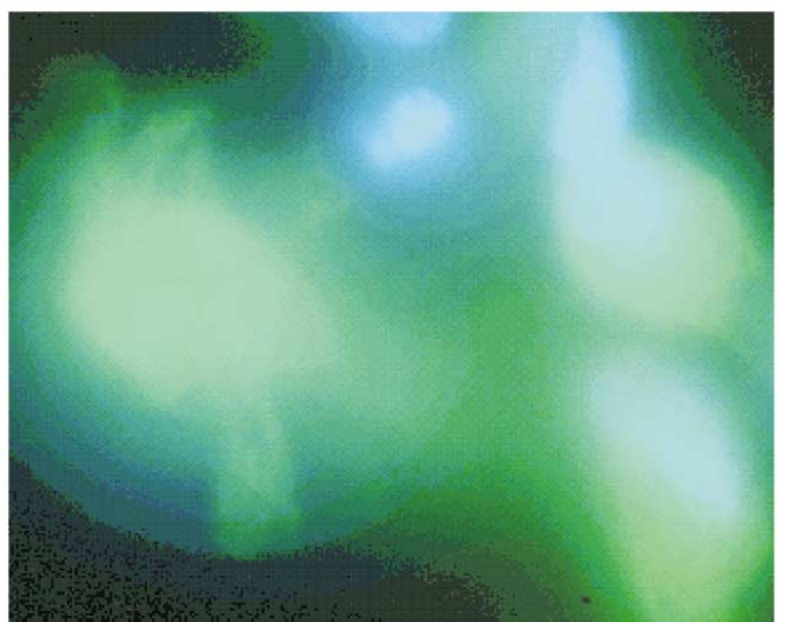

Plate 1. Detection of the GFPLuc protein by fluorescence microscopy. EPCtiHSP70 cells in control conditions (left) or after $1 \mathrm{~h}$ of heat shock treatment (right) are shown. The cells were stained with DAPI (blue fluorescence) and the green fluorescence due to GFPluc expression was superimposed.
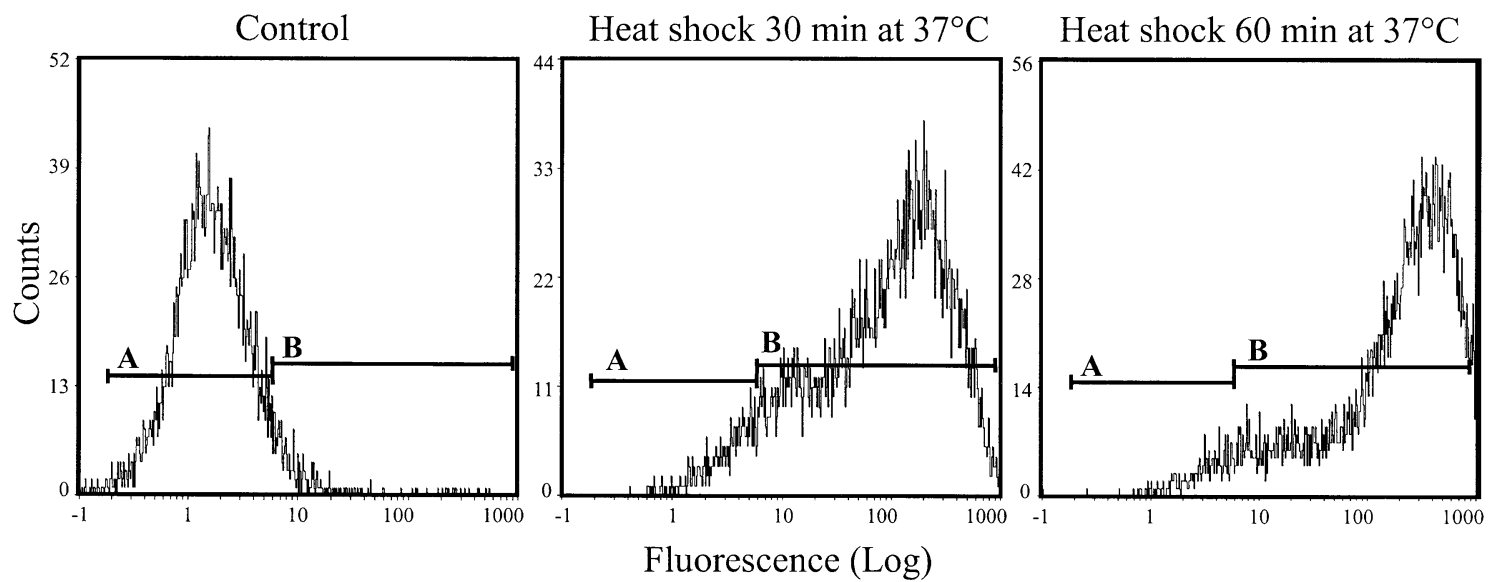

Fig. 2. Quantification of the GFPluc fluorescence by flow cytometry. Control EPCtiHSP70 cells or cells treated for 30 or 60 min at $37{ }^{\circ} \mathrm{C}$ were analyzed in a flow cytometer and the number of cells was plotted against the intensity of their fluorescence. The fluorescence scale is logarithmic. 
$750 \mu \mathrm{M}$ and produced a 100 -fold stimulation at $2 \mathrm{mM}$ (Fig. 3A).

We also tested various metal ions for their effects on the HSP70 promoter (Fig. 3B). Mercury, zinc, copper and cadmium salts were all able to induce the reporter gene expression. The detectable concentrations and the intensities of the signal were different (summarized in Table 1). Very low levels of mercury ions $(5 \mu \mathrm{M})$ already led to a clear induction, but the maximal signal obtained at $75 \mu \mathrm{M}$ was also very low, again due to cellular death. In contrast, other ions such as lead, cobalt, lithium and nickel failed to induce the expression of the reporter gene. Several other organic or inorganic compounds
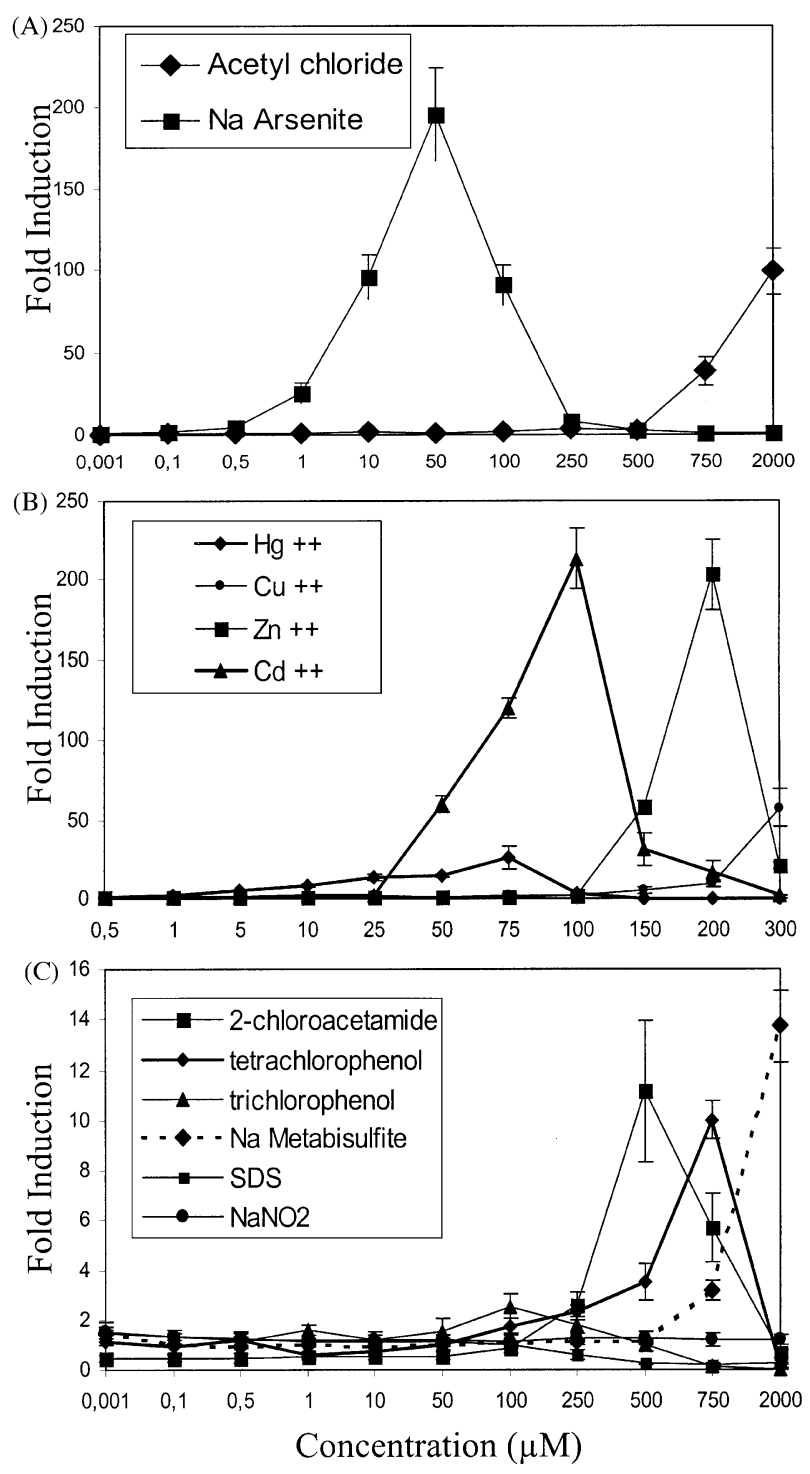

Fig. 3. Response of EPCtiHSP70 cells after exposure to various chemical stressors. The cells were seeded into 96-well plates, treated for $12 \mathrm{~h}$ with various concentrations of the indicated compounds and allowed to recover for $4 \mathrm{~h}$. The luciferase activity in the cell lysates was determined, normalized to total DNA content and the fold induction relative to untreated cells was calculated. All experiments were performed in quadruplicate (mean \pm S.D.). were tested, again showing various induction levels and sensitivities (Fig. 3C). Tetrachlorophenol, chloroacetamide and sodium metabisulfite caused low, but detectable promoter stimulation, while trichlorophenol, sodium dodecyl sulfate or sodium nitrite was ineffective at the concentrations used.

\section{Discussion}

We present the utilization of a plasmid construct containing the heat shock inducible HSP70 promoter from tilapia controlling the transcription of the GFPLuc fusion protein. The presence of this protein can be detected either by luminometry based on the luciferase activity, or by detecting the fluorescence of the GFP. This construct was used to generate a stable transformed cell line from carp epithelial cells.

Characterization of the EPCtiHSP70 cell line revealed a very strong stimulation of reporter gene expression (up to 800-fold) after heat shock, the response was highest after treatment for $1 \mathrm{~h}$ at $37^{\circ} \mathrm{C}$ and the signal decreased about $8 \mathrm{~h}$ after the end of the heat shock. Protection of the cells by a preceding cellular stress, probably due to the presence of residual heat shock proteins in the cell (Jaattela, 1999; Samali et al., 1999), was also observed on the integrated reporter gene. This response behavior is similar to that observed in other whole organisms (Krone and Heikkila, 1988; Misra et al., 1989; Arai et al., 1994) or in transient expression experiments (Vogel et al., 1997).

In addition to analyzing the increase of luciferase activity in extracts from treated cells, the EPCtiHSP70 cell line also offers the possibility to observe the stimulation of green fluorescence in the living cell. This very rapid assay implies inspection of single cells, either by fluorescence microscopy or flow cytometry. It is conceivable to follow the response in the same cell during the cell cycle or after repeated consecutive stress events. Such a direct observation will possibly shed new light on the mechanisms involved in stress response.

A collection of inorganic and organic toxics was tested for their ability to induce the heat shock response in the EPCtiHSP70 cells. Known stimulators of HSP70 genes $\left(\mathrm{Cd}^{2+}, \mathrm{Zn}^{2+}, \mathrm{Hg}^{2+}, \mathrm{AsO}_{3}\right)$ were able to induce a strong response, at different concentrations and with various lowest detection levels (see Table 1). Other, mainly organic compounds were less efficient and yielded a maximal 10-fold response. Notably, 2 mм 2,4,5trichlorophenol was not detected in our assay, although a significant response has been reported with this compound at $50 \mu \mathrm{M}$ in other cell systems (Fischbach et al., 1993, Aït-Aïssa et al., 2000). Considering the strong signals observed in EPC cells with other compounds, this lack of sensitivity is probably due to a higher resistance of these cells to specific compounds. Other cell 
Table 1

Summary of the luciferase signals and the mortality induced by various stressors ${ }^{\mathrm{a}}$

\begin{tabular}{|c|c|c|c|c|c|c|}
\hline Stressor & $I \max$ & $(\mu \mathrm{M})$ & $\mathrm{I} \min$ & $(\mu \mathrm{M})$ & $\mathrm{LC}(\mu \mathrm{M})$ & $\%$ \\
\hline $\mathrm{CdCl}_{2}$ & $213 \pm 19$ & 100 & $60 \pm 5$ & 50 & 150 & 60 \\
\hline $\mathrm{ZnCl}_{2}$ & $203 \pm 22$ & 200 & $58 \pm 4$ & 150 & 200 & 68 \\
\hline $\mathrm{CuCl}_{2}$ & $57 \pm 12$ & 300 & $5 \pm 2$ & 150 & - & - \\
\hline $\mathrm{HgCl}_{2}$ & $26 \pm 7$ & 75 & $5 \pm 0.4$ & 5 & 50 & 75 \\
\hline $\mathrm{NaAsO}_{3}$ & $196 \pm 29$ & 50 & $4 \pm 0.9$ & 0.5 & 100 & 27 \\
\hline Acetyl chloride & $99 \pm 9$ & 2000 & $3.2 \pm 0.3$ & 500 & 500 & 42 \\
\hline 2-Chloroacetamide & $11 \pm 3$ & 500 & $2.5 \pm 0.2$ & 250 & 250 & 67 \\
\hline 2,3,4,5-Tetrachlorophenol & $10 \pm 0.8$ & 750 & $2.3 \pm 0.2$ & 250 & - & - \\
\hline Sodium metabisulfite & $14 \pm 1.4$ & 2000 & $3.2 \pm 0.4$ & 750 & 750 & 58 \\
\hline Sodium dodecyl sulfate & - & - & - & - & 750 & 13 \\
\hline 2,4,5-Trichlorophenol & - & - & - & - & 750 & 47 \\
\hline $\mathrm{Pb}(\mathrm{NO} 3)_{2}$ & - & - & - & - & - & - \\
\hline $\mathrm{NaNO}_{2}$ & - & - & - & - & - & - \\
\hline $\mathrm{CoCl}_{2}$ & - & - & - & - & - & - \\
\hline $\mathrm{NiCl}_{2}$ & - & - & - & - & - & - \\
\hline $\mathrm{LiCl}$ & - & - & - & - & - & - \\
\hline
\end{tabular}

a Various concentrations of the different compounds (stressors) were tested for luciferase induction and the amount of cell death was estimated by measuring the DNA content of the cell lysates. Maximal induction (I max) and the minimal detected signal (I min) are indicated as well as the concentrations at which they were observed $(\mu \mathrm{M})$. The lowest concentrations at which a decrease in DNA content was observed (LC) are given as well as the fraction of surviving cells $(\%)$ at this concentration. $(-)$ indicates that no signal or no mortality was observed for this compound in the concentration range tested.

lines presenting a different pattern of stress response must be envisaged in order to extend the spectrum of compounds to be detected. Another aspect of cell-based detection systems is the relation between the detected signal and the cytotoxicity of the investigated compound. In Table 1, the concentrations causing significant cell death and the fraction of residual cells are indicated for each chemical tested. When these concentrations (LC) are compared to those causing the HSP response, basically two types of situations were observed. First the agents causing very high HSP stimulation (heat shock, $\mathrm{Cd}^{2+} ; \mathrm{Zn}^{2+} ; \mathrm{Cu}^{2+} ; \mathrm{NaAsO}_{3}$ ) did so at concentrations clearly below that causing significant cell death, suggesting that they induce HSF activation by a direct mechanism inside the cell. This stimulation is probably triggered by intracellular protein aggregation due to exposure of hydrophobic residues upon heat shock or to thiol modification through glutathione depletion upon oxidative stress (Freeman et al., 1999). Cell death at higher concentrations probably results from the incapacity of the cell to cope with the corresponding levels of protein denaturation. Other compounds caused a more moderate response at concentrations that were also cytotoxic. Particularly the organic compounds 2-chloroacetamide and 2,3,4,5tetrachlorophenol caused significant cell death at the concentrations inducing the highest signal, probably explaining the low signals (10-fold) observed. This observation is consistent with previous reports (Neuhaus-Steinmetz and Rensing, 1997; Aït-Aïssa et al., 2000), which also revealed a high cytotoxicity of similar compounds. Moreover, they found a close correlation between the lipophilicity of the chemical and its cyto- toxicity and proteotoxicity (the latter as revealed by HSP stimulation). These results suggest that these compounds, due to their chemical properties, cause cell death by one particular mechanism (e.g. lipophilic compounds could integrate into cellular membranes) and stimulate the HSP response by a different mechanism (e.g. by exposing the hydrophobic core of intercellular proteins). Alternatively, the HSP70 promoter is induced as a consequence of cell death or apoptosis. In this respect, it is interesting to note that the small GTPase Rac-1, implicated in actin cytoskeletal organization, growth factor-induced membrane ruffling, cell proliferation and stress response, is also involved in the activation of HSF by some, but not all HSP inducers (Han et al., 2001).

In conclusion, we present a cell line that produces a fluorescent signal and synthesizes luciferase in response to various cellular stressors. In conjunction with other, more specific assays, this or similar fish cell lines might be useful to study the impact of environmental pollutants on living cells or to evaluate the toxic potential of complex mixtures that are typical for aquatic environmental samples.

\section{Acknowledgements}

We are grateful to R.N. Pay (Denver, USA) for kindly providing the GFP-Luciferase gene. This work was supported by the "Région Wallone (ULg 1815)"; the "Services Fédéraux des Affaires Scientifiques, Techniques et Culturelles" (PAI P4/30 and "Actions de Recherche Concertées": 95/00-193); the Fonds National de la 
Recherche Scientifique (FNRS) (-3.4537.93 and -9.4569.95) and the EU (no. BIO4-CT97-0554). M.M. is a "Chercheur qualifié" at the Fonds National de la Recherche Scientifique (FNRS). A.M. held fellowships from "CGRI" and "ULg patrimoine".

\section{References}

Aï-Aïssa, S., Porcher, J., Arrigo, A., Lambre, C., 2000. Activation of the hsp70 promoter by environmental inorganic and organic chemicals: relationships with cytotoxicity and lipophilicity. Toxicology 145, 147-157.

Arai, A., Mitani, H., Naruse, K., Shima, A., 1994. Relationship between the induction of proteins in the HSP70 family and thermosensitivity in two species of Oryzias (Pisces). Comparative Biochemistry and Physiology-B. Biochemistry and Molecular Biology 109, 647-654.

Brasier, A.R., Tate, J.E., Habener, J., 1989. F Optimized use of the firefly luciferase assay as a reporter gene in mammalian cell lines. Biotechniques 7, 1116-1122.

Day, R.N., Kawecki, M., Berry, D., 1998. Dual-function reporter protein for analysis of gene expression in living cells. Biotechniques $25,848-856$.

De Wachter, B., Scholliers, A., Blust, R., 1998. Semiquantitative immunoblot detection of $70 \mathrm{kDa}$ stress proteins in the carp Cyprinus carpio. Bulletin of Environmental Contamination and Toxicology 60, 37-44.

Dunlap, D.Y., Matsumura, F., 1997. Development of broad-spectrum antibodies to heat shock protein 70 s as biomarkers for detection of multiple stress by pollutants and environmental factors. Ecotoxicology and Environmental Safety 37, 238-244.

Fijan, N., Sulimanavoic, D., Bearzotti, M., Muzinic, M.D., Zwilenberg, L.O., Chilmonzyk, S., Vautherot, J.F., Kinkelin, P., 1983. Some properties of the Epithelioma papulosum cyprini (EPC) cell line from carp Cyprinus carpio. Annales de l'Institut Pasteur/Virology 134, 207-220.

Fischbach, M., Sabbioni, E., Bromley, P., 1993. Induction of the human growth hormone gene placed under human hsp70 promoter control in mouse cells: a quantitative indicator of metal toxicity. Cell Biology and Toxicology 9, 177-188.

Freeman, M.L., Borelli, M.J., Meredith, M.J., Lepock, J.R., 1999. On the path to the heat shock response: destabilization and formation of partially folded protein intermediates, a consequence of protein thiol modification. Free Radical Biology and Medicine 145, 147157.

Han, S.I., Oh, S.Y., Woo, S.H., Kim, K.H., Kim, J.-H., Kim, H.D., Kang, H.S., 2001. Implication of a small GTPase Racl in the activation of c-Jun terminal kinase and heat shock factor in response to heat shock. Journal of Biological Chemistry 276, 18891895.
Hartl, U.F., 1996. Molecular chaperones in cellular protein folding. Nature 381, 571-580.

Jaattela, M., 1999. Escaping cell death: survival proteins in cancer. Experimental Cell Research 248, 30-43.

Krone, P.H., Heikkila, J.J., 1988. Analysis of hsp 30, hsp 70 and ubiquitin gene expression in Xenopus laevis tadpoles. Development 103, $59-67$.

Misra, S., Zafarullah, M., Price-Haughey, J., Gedamu, L., 1989. Analysis of stress-induced gene expression in fish cell lines exposed to heavy meals and heat shock. Biochimica et Biophysica Acta 1007, 325-333.

Molina, A., Biemar, F., Muller, F., Iyengar, A., Prunet, P., Maclean, N., Martial, J.A., Muller, M., 2000. Cloning and expression analysis of an inducible HSP70 gene from tilapia fish. FEBS Letters 474, 5-10.

Molina A., Di Martino E., Martial J. A., Muller M., 2001. Heat shock stimulation of a tilapia fish HSP70 promoter is mediated by a distal element. Biochemical Journal 356, 353-359.

Morimoto, R.I., 1993. Cells in stress: transcriptional activation of heat shock genes. Science 259, 1409-1410.

Morimoto, R.I., 1998. Regulation of the heat shock transcriptional response: cross talk between a family of heat shock factors, molecular chaperones, and negative regulators. Genes and Development 2, 3788-3796.

Neuhaus-Steinmetz, U., Rensing, L., 1997. Heat shock protein induction by certain chemical stressors is correlated with their cytotoxicity, lipophilicity and protein-denaturing capacity. Toxicology 123, 185-195.

Rabindran, S.K., Haroun, R.I., Clos, J., Wisniewski, J., Wu, C., 1993. Regulation of heat shock factor trimer formation: role of a conserved leucine zipper. Science 259, 230-234.

Ritossa, F., 1962. A new puffing pattern induced by heat shock and DNP in Drosophila. Experientia 18, 571-573.

Samali, A., Holmberg, C.I., Sistonen, L., Orrenius, S., 1999. Thermotolerance and cell death are distinct cellular responses to stress: dependence on heat shock proteins. FEBS Letters 461, 306-310.

Sistonen, L., Sarge, K.D., Morimoto, R.I., 1994. Human heat shock factors 1 and 2 are differentially activated and can synergistically induce hsp70 gene transcription. Molecular and Cellular Biology 14, 2087-2099.

Steiner, E., Kleinhappl, B., Gutschi, A., Marth, E., 1998. Analysis of hsp70 mRNA levels in HepG2 cells exposed to various metals differing in toxicity. Toxicology Letters 96-97 169-176.

Todd, M.D., Lee, M.J., Williams, J.L., Nalezny, J.M., Gee, P., Benjamin, M.B., Farr, S.B., 1995. The CAT-Tox (L) assay: a sensitive and specific measure of stress-induced transcription in transformed human liver cells. Fundamental and Applied Toxicology 28, 118-128.

Vincent, R., Goegan, P., Johnson, G., Brook, J.R., Kumarathasan, P., Bouthillier, L., Burnett, R.T., 1997. Regulation of promoter-CAT stress genes in HepG2 cells by suspensions of particles from ambient air. Fundamental and Applied Toxicology 39, 18-32.

Vogel, P., Dux, E., Wiessner, C., 1997. Effect of heat shock on neuronal cultures: importance of protein synthesis and HSP72 induction for induced tolerance and survival. Metabolic Brain Disease 12, 203-217. 